\title{
CLIMATIC RECORD FROM AN ICE MARGIN AREA IN EAST ANTARCTICA
}

\author{
by
}

T. D. Yao,

(Institute of Glaciology and Geocryology, Academia Sinica, Lanzhou, People's Republic of China)

$$
\text { J.R. Petit, }
$$

(Laboratoire de Glaciologie et Géophysique de l'Environnement, CNRS, BP 96, 38402 St Martin d'Hères Cedex, France and Laboratoire de Géochimie Isotopique, CEA/IRDI/DESICP/DLPC-CEN Saclay 91191, Gif sur Yvette Cedex, France)

\section{J. Jouzel,}

(Laboratoire de Géochimie Isotopique, CEA/IRDI/DESICP/DLPC-CEN Saclay 91191, Gif sur Yvette Cedex, France and Laboratoire de Glaciologie et Géophysique de l'Environnement, CNRS, BP 96, 38402 St Martin d'Hères Cedex, France)

\section{Lorius and P. Duval}

(Laboratoire de Glaciologie et Géophysique de l'Environnement, CNRS, BP 96, 38402 St Martin d'Hères Cedex, France)

\section{ABSTRACT}

Deuterium content, microparticle concentration, ice crystal size and bubble concentration have been studied along an $82 \mathrm{~m}$ ice core drilled down to the bedrock in the ice-sheet margin in East Antarctica. The Last Glacial Maximum (LGM) is distinctly marked by low deuterium content, high concentration of microparticles, small ice crystals and high bubble concentrations. This core covers a significant part of the Last Glacial Period with ice from a warmer period recovered around a depth of $60 \mathrm{~m}$.

\section{INTRODUCTION}

A large number of ice cores have been recovered for studies of the past evolution of climatic, environmental and atmospheric conditions in Antarctica. Ice cores have also been recovered from marginal areas of both the Antarctic and Greenland ice sheets (Lorius, 1968; Lorius and others, 1968; Merlivat and others, 1967; Lorius and Merlivat, 1977; Budd and Morgan, 1977; Grootes and Stuiver, 1986, 1987; Clausen and Stauffer, 1988). So far, the interpretations of these marginal cores have mainly been based on isotope content and limited to the transition from the LGM to the Holocene because of the complicated situation in the margin caused by dynamic and non-dynamic processes.

The present paper deals with a study of the "Caroline" marginal ice core, in the vicinity of Dumont d'Urville Station $\left(66^{\circ} 40^{\prime} \mathrm{S}, 140^{\circ} 01^{\prime} \mathrm{E}\right)$, Terre Adélie. Mean annual temperature is of the order of $-10^{\circ} \mathrm{C}$. Other cores have already been recovered in this area, i.e. from the coast inland, G1, G2 (Merlivat and others, 1967), A3 (Lorius and others, 1968) and D10, a $303 \mathrm{~m}$-deep core drilled $5 \mathrm{~km}$ from the coast during the 1973-74 summer (Lorius and Merlivat, 1977). The Caroline core was recovered near G1 about $500 \mathrm{~m}$ from the coast, in January 1987. It reached bedrock and had a length of $82 \mathrm{~m}$. No cracks were found in this core. The lowest $6 \mathrm{~m}$ near bedrock is rich in pink debris, salt and sand.

The objectives of the Caroline drilling were twofold: (1) to better understand through a comparison between series of cores drilled in a marginal area the ice dynamics and the long-term ice dynamics-climate interaction for such a region; (2) to document the possibility of obtaining easily accessible glacial ice in large amounts as required by some analyses of trace species. For these two purposes the drilling of the core was supplemented by a series of surface transects. Easy access to basal ice opens the possibility of applying isotopic and other methods for studying processes occurring at the glacial bed (Jouzel and Souchez, 1982; Souchez and others, 1988).

In this paper, we focus on data obtained along the $82 \mathrm{~m}$ core. Our strategy was to apply a full spectrum of methodologies to study this marginal core and to compare the paleoclimatic and paleoenvironmental records with that of the Dome C and Vostok deep ice cores drilled on the Antarctic Plateau. Here we successively present and discuss the continuous isotopic profile (deuterium content) and data relative to microparticle concentration, ice crystal size and bubble concentration.

\section{EXPERIMENTS AND RESULTS}

The ice core drilled in January 1987 was transported in April 1987 to Grenoble at a temperature around $-15^{\circ} \mathrm{C}$ and stored in a cold room. Ice crystal measurements were made immediately after the ice core was transported to Grenoble. Bubble concentrations were measured from thin sections. Microparticle concentrations were then measured by Coulter counter and optical counting methods. Isotope content measurements (deuterium) were processed at LGI/Saclay.

\section{Deuterium isotope record}

Samples for isotope content analysis were prepared in the field by cutting continuous slices along the ice core. The slices were then cut into samples of about $40 \mathrm{~cm}$, which were kept frozen until measurement to prevent evaporation.

Although ${ }^{18} \mathrm{O}$ is generally used in glaciology studies, Jouzel and others (1987) have proposed that the deuterium isotope is a slightly better indicator of temperature change than ${ }^{18} \mathrm{O}$. In the present paper, the results are presented in deuterium content expressed in parts per mil with respect to Standard Mean Ocean Water (SMOW). The deuterium profile is reported with respect to depth on Figure $1 \mathrm{~b}$; on Figure 2a a smooth curve (obtained using a spline function) is superimposed on this profile. The following features are observed.

From the ice surface to the depth of $21 \mathrm{~m}$, the deuterium isotope content fluctuates between $-130 \%$ and 

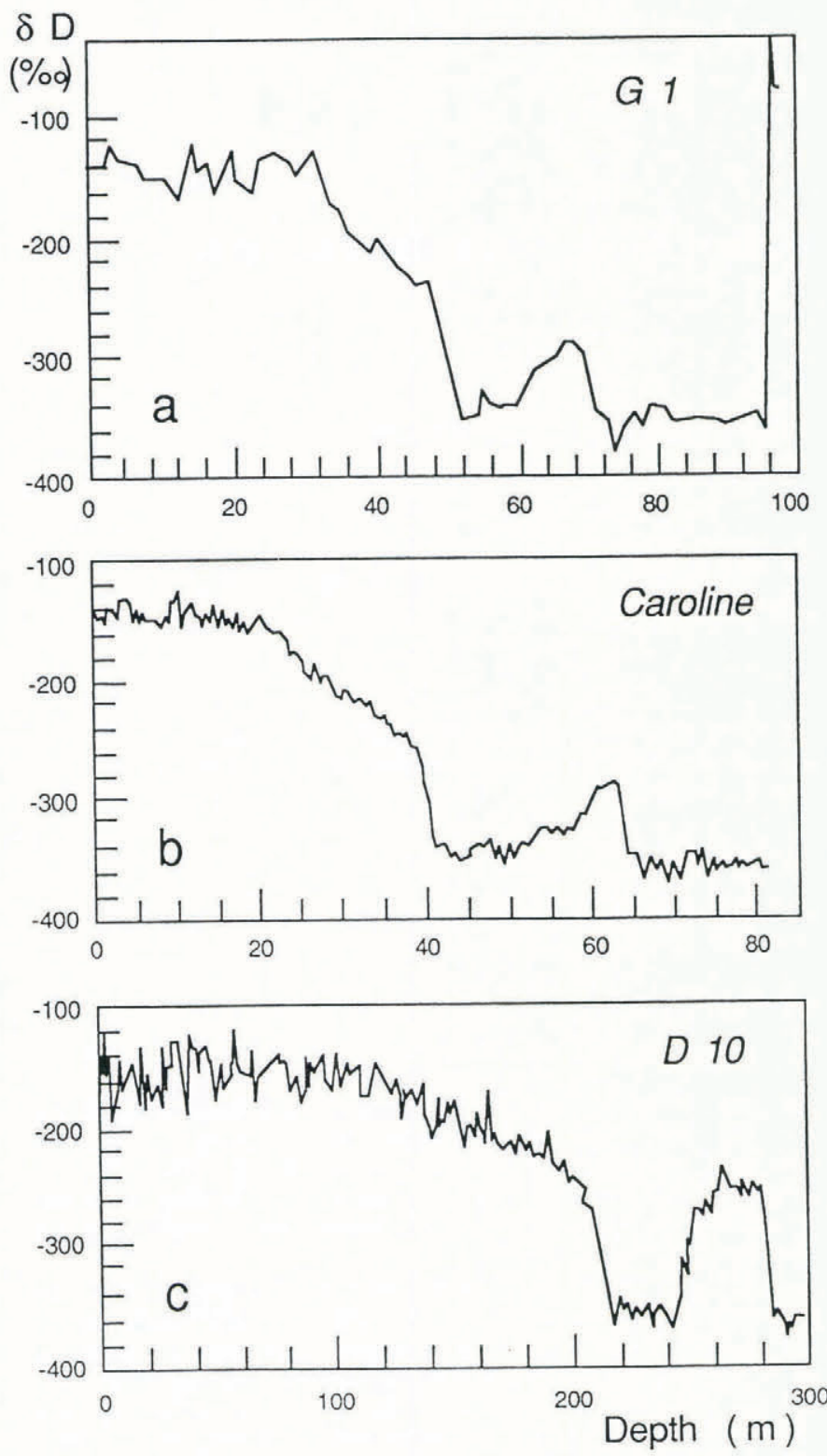

Fig. 1. Deuterium content profiles from the marginal area in Terre Adélie (East Antarctica) with respect to depth at G1 (Merlivat and others, 1967), Caroline (this work) and D10 (Lorius and Merlivat, 1977).

$-155 \%$. There is a gradual marked decrease towards a value of about $-250 \%$ near $39 \mathrm{~m}$. The deuterium content then decreases abruptly down to $-345 \%$ at $42 \mathrm{~m}$ and continues to decrease to $-356 \%$ around $45 \mathrm{~m}$. Below $48 \mathrm{~m}$ the deuterium content follows a steadily increasing trend and reaches a value of about $288 \%$ at $63 \mathrm{~m}$. This secondary maximum is also followed by a relatively sharp decrease to $-373 \%$ (the lowest deuterium content) at $67 \mathrm{~m}$, and then followed by values around $-360 \%$ down to the core bottom.

Along this profile, several stages can be distinguished:

(A) present stage with a mean deuterium isotope content of 146\%:

(B) low isotope content stage between 40 and $50 \mathrm{~m}$ with an average isotope content of $-350 \%$ :

(C) High isotope content stage between 60 and $64 \mathrm{~m}$ with an isotope content of $-294 \%$ :

(D) the stage with the lowest isotope contents, between 67 and $71 \mathrm{~m}$, with an average isotope content of $-363 \%$.

For the sake of comparison, deuterium profiles at G1 (Merlivat and others, 1967) and D10 (Lorius and Merlivat, 1977) are reported on Figure 1 with respect to depth. As may be expected given the short distance between these two

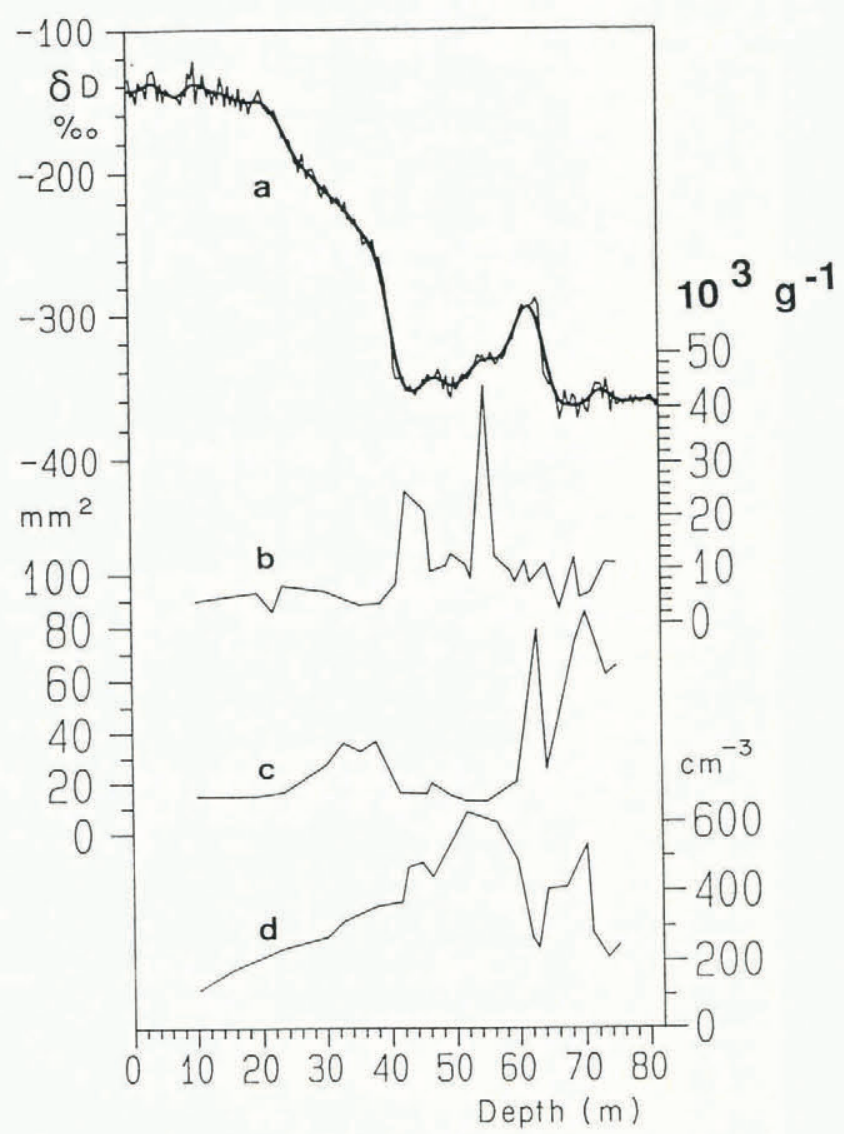

Fig. 2. Measured parameters along the Caroline ice core with respect to depth: (a) deuterium content (a smooth curve is superimposed on detailed curve); (b) microparticle concentration; (c) crystal size; (d) bubble concentration.

cores (less than $200 \mathrm{~m}$ ), Gl and Caroline deuterium profiles present strong similarities. A noticeable difference is the presence at the bottom of the G1 core of an isotopically-rich layer with a deuterium content close to that of sea water which is quite certainly due to basal freezing of sea water (Merlivat and others, 1967). In both cores, the transition from high (at the top of the core) to low isotopic values occurs in two stages. This morphological feature is observed also (but for different depths) in the D10 core. In the line of previous interpretations of G1, G2 and D10 isotopic profiles (Lorius and Merlivat, 1977; Raynaud and others, 1979; Grootes and Stuiver, 1986, 1987), one can safely assume that the low values recorded around $45 \mathrm{~m}$ in Caroline correspond to ice accumulated during the Last Glacial Maximum (LGM) about 18000 years ago. As discussed below, this assumption is fully confirmed by the present multiparametric study performed along the Caroline core.

\section{Microparticle data}

Fifty samples were measured (approximately one ice sample every $1.5 \mathrm{~m}$ along the ice core). The sample preparation followed the procedure described by Thompson (1977) and Petit and others (1981) with special care to avoid contamination since the ice in the marginal area is very clean. There are several sources of contamination in the laboratory. Among these possible sources, DFW (de-ionized filtered water) and $\mathrm{NaCl}$ solution contamination are the most serious. To avoid such contamination, the $\mathrm{NaCl}$ solution was filtered several times with filters of $0.22 \mu \mathrm{m}$ in diameter (the microparticles to be measured are larger than $0.4 \mu \mathrm{m})$. The DFW supply was checked by a blank each time before rinsing samples. Even so, some samples were still contaminated. The contaminated samples were removed after checking under an optical microscope. The prepared samples were measured individually with a Coulter counter and optical counting, as discussed in detail in Mounier (1988). The results were obtained by measuring the total number of microparticles larger than $0.4 \mu \mathrm{m}$ and the volume 
distribution, by Coulter counter. The total number was also determined by optical counting, which, although limited to microparticles larger than $0.5 \mu \mathrm{m}$, provides a useful check of the contamination and the Coulter counter results. Figure $2 b$ shows the total number of microparticles. The microparticle concentration is very low from 10 to $39 \mathrm{~m}$ with an average number of $3900 \mathrm{~g}^{-1}$ and with the lowest value of $400 \mathrm{~g}^{-1}$ near the surface. Between 40 and $46 \mathrm{~m}$, there is a microparticle concentration peak followed by a sharp decrease from 46 to $54 \mathrm{~m}$. There is another strong peak at $55 \mathrm{~m}$. These two well marked peaks centered around 43 and $55 \mathrm{~m}$ are also detected in the curve of volume distribution (not shown).

Studies of microparticle concentration carried out on Antarctic ice cores have shown secular variations in relation with climate (Thompson and Mosley-Thompson, 1981; Petit and others, 1981) with low concentration during warm periods (e.g. Holocene) and high values during cold periods (e.g. LGM). The non-soluble microparticles are thought to be mainly representative of the small sized fraction $(\mathrm{r} \sim 1 \mu \mathrm{m})$ of the dust produced by the arid and semi-arid areas of the three continents of the Southern Hemisphere (Petit and others, 1981; Briat and others, 1982; Gaudichet and others, 1986). The high concentration of dust found during the LGM would be the result of the continental aridity expansion coupled with wind speed over desert areas and meridional transport efficiency of the atmospheric circulation (Petit and others, 1981).

Published data are generally limited to the last stage of the Last Glacial Period. So far, only the Vostok ice core extends back to the previous interglacial period. The profile of the dust displays two high peaks: one corresponding to the LGM and the other around $60 \mathrm{ka}$ B.P. (De Angelis and others, 1987; Legrand and others, 1988; Mounier, 1988). So, assuming that the variation in micro-particle concentration followed the same general features over all of Antarctica, it is, in the Caroline ice core, reasonable to attribute the peak at the depth of $43 \mathrm{~m}$ to the LGM and possibly the second peak at a depth of $55 \mathrm{~m}$ to the peak around $60 \mathrm{ka}$ B.P. in the Vostok ice core. Although the microparticle concentration record on Figure $2 \mathrm{~b}$ is preliminary, the bottom of the Caroline core (below $55 \mathrm{~m}$ ) could be older than $60 \mathrm{ka} \mathrm{B.P.}$. if the dust profile is confirmed.

\section{Crystal size}

Crystal size determination generally involves measurements of either the diameters or cross-sectional areas of ice crystals. Of several methods applied to the studies of ice crystals, the most popular appears to be the computation of cross-sectional area of crystals (expressed here in $\mathrm{mm}^{2}$ ) in a specified area on photographs of thin sections taken under cross-polarized light (Duval and Lorius, 1980; Young and others, 1985; Xie, 1985). At least 100 crystals were measured for each thin section in this study. In some parts of the ice core, crystals were so large that it was impossible to count 100 crystals on one thin section. In this case, another thin section was cut $10-15 \mathrm{~cm}$ from the first one.

A diagram of crystal size versus depth is shown on Figure 2c. The size first increases with depth from $13 \mathrm{~mm}^{2}$ at $20 \mathrm{~m}$ up to $37 \mathrm{~mm}^{2}$ at $38 \mathrm{~m}$. Then a clear sharp decrease occurs between 38 and $43 \mathrm{~m}$ where the crystal size is only $12 \mathrm{~mm}^{2}$. Between 43 and $60 \mathrm{~m}$, crystal size maintains a value of about $12 \mathrm{~mm}^{2}$. Below $60 \mathrm{~m}$, crystal size varies between $20 \mathrm{~mm}^{2}$ and very large values up to $85 \mathrm{~mm}^{2}$. Obviously the 38 to $43 \mathrm{~m}$ transition corresponds also to the rapid change in the deuterium profile.

Several explanations have been proposed to explain the fine-grained texture of glacial ice and the causes have not yet been clarified (Gow and Williamson, 1976; Koerner and Fisher, 1979; Duval and Lorius, 1980; Herron and Langway, 1982; Herron and others, 1985; Young and others, 1985). Gow and Williamson (1976) suggested that the fine-grained structure in the Byrd ice core could be due to strong shear deformation. Xie (1985) found that at Law Dome the fine-grained structure (with a single maximum fabric) was developed under the influence of the horizontal shear stress increasing with depth. Koerner and Fisher (1979) considered in the Devon Ice Cap that the crystal size was related to impurity changes.

The effect of microparticles, bubbles and impurities on grain growth has been very well analysed by Alley and others $(1986 \mathrm{a}, \mathrm{b})$. Nevertheless, in the Dome C ice core the very close correlation between isotope content and crystal growth rate suggests that ice dynamics do not play an important role. Petit and others (1987) concluded that growth rate is mainly driven by a "built-in" memory of the temperature prevailing at the time of crystal deposition.

But in the Caroline core the grain growth process, as driven by the grain boundary energy, should not be invoked since the strain energy is probably high in comparison with the free energy at the grain boundaries. In consequence the paleoclimate information deduced from variations in the crystal growth rate by Petit and others (1987) cannot be applied here. So, in Caroline, the 38 to $43 \mathrm{~m}$ change in crystal size which corresponds to the Last Glacial to Holocene transition, is possibly due to a combination of the effects of the "built-in" memory and strain energy. Obviously, the deepest part of the core is even more complicated since the very large crystals at this depth could signal zones of dead ice or a recrystallized zone.

\section{Bubble concentration}

Bubble concentrations were measured from photographs $(\times 10)$ of thin sections. Thin sections for bubble studies were prepared in a cold room in a similar way to the preparation of thin sections for crystal measurements. The thickness of each thin section was generally about $1 \mathrm{~mm}$. In a given area of the thin sections at least 100 bubbles larger than $0.1 \mathrm{~mm}$ were measured. The thickness of the sections was measured in four planes in order to get a bubble concentration per volume of ice.

The profile is shown in Figure 2d. From 10 to $50 \mathrm{~m}$ there is a general increase and the concentration varies from 200 up to $630 \mathrm{~cm}^{-3}$. Below this depth, the concentration is $200 \mathrm{~cm}^{-3}$ around 63 and $73 \mathrm{~m}$. It is interesting to note that the maxima in bubble concentration occur for ice formed under glacial conditions. However, the sharp transition from Last Glacial to Holocene observed for isotopes, microparticle concentrations and crystal size profiles is not observed in the bubble concentration profile. Bubbles in polar region ice sheets are formed by the entrapment of atmospheric air between snow flakes during the process of accumulation. Since air bubbles become isolated from the atmosphere only during the transition from firn to ice, firn temperature, grain size and snow accumulation rate must be important factors in the relationship between bubble concentration and climate. However, recrystallization could hide the original bubble concentration. This is probably true in the Caroline core deeper than $63 \mathrm{~m}$, where ice could be dead and very old.

\section{DISCUSSION}

We will focus the discussion on the ensemble of results obtained along the Caroline core and particularly on the climatic transition from the LGM to the Holocene and on the relatively warm period recorded prior to the LGM (between 60 and $64 \mathrm{~m}$ ).

Figure 2 displays the clear relationship between climatic change (indicated by deuterium content) and ice physical properties. From 39 to $44 \mathrm{~m}$, where the deuterium content decreases abruptly, microparticle concentration increases from 6000 to $20000 \mathrm{~g}^{-1}$, ice crystal size decreases by a factor of more than three but bubble concentation is still increasing. Between 50 and $60 \mathrm{~m}$, the deuterium content shows a gradual slow increase, ice crystal size maintains the same value, microparticle concentration exhibits a peak at $55 \mathrm{~m}$ and bubble concentration decreases below $51 \mathrm{~m}$.

In coastal sites like G1, Caroline and D10 (Fig. 1), we expect to find with depth a continuous sequence of ice originating from increasing distances from the coast and successively higher elevations. The constant deuterium values observed in the upper part (down to $20 \mathrm{~m}$ in Caroline) are due to the constant deuterium value observed from the coast to about $30 \mathrm{~km}$ upstream of the drilling site (Lorius and Merlivat, 1977). The first stage characterized by a gradual deuterium decrease (from 20 to $39 \mathrm{~m}$ in Caroline) still corresponds to ice accumulated during the Holocene period, as supported by the ice crystal size increase with depth and the absence of significant variation in the microparticle concentration. The deuterium decrease is essentially 
of dynamic origin from further inland, higher and therefore colder origins with increasing depth. This should hold also for bubble concentration variation.

The amplitude of the deuterium shift associated with the second stage marked by a rapid deuterium decrease ( $75 \%$ at Caroline between 39 and $41.5 \mathrm{~m}$ ) is larger than that recorded at Dome $\mathrm{C}$ and Vostok, which is about 60\% between full glacial conditions and the Holocene period. In these two sites located on the central Antarctic Plateau this isotopic shift is interpreted as being essentially of climatic origin, i.e. corresponding to a surface temperature change of $9^{\circ} \mathrm{C}$ (Jouzel and others, 1987, 1989). An additional shift, recorded in coastal areas, is linked with the change in the origin of the ice between the LGM and the Holocene but also with concurrent lowering of the ice sheet. Although there is some debate in terms of a quantitative interpretation based on D10 data (Raynaud and others, 1979; Grootes and Stuiver, 1987, 1988; Jouzel and others, 1989) it is well accepted that in this coastal area the ice cap was thicker during the LGM than during the Holocene. The isotopic data available on Caroline do not permit us, at the moment, to assess this particular aspect. New information with respect to that deduced from D10 results and this point will not be discussed further in the present article.

Relatively high deuterium values accompanied by large ice crystals at $63 \mathrm{~m}$, low microparticle concentration and low bubble concentration are recorded in the Caroline ice core between 60 and $64 \mathrm{~m}$. There are two possible explanations for this feature. One possibility is that the ice here was deformed by dynamic processes such as shearing, folding or thrusting which may result in an inversion or repetition of isotopic stratigraphy. The other possibility is that this feature may be from a warm period prior to the LGM. The following factors lead us to favour the second possibility:

(A) Deuterium contents in the two transitions from 39 to $41.4 \mathrm{~m}$ and from 63 to $67 \mathrm{~m}$ are different in value, which means that this feature is not a consequence of the inversion or repetition of isotopic stratigraphy caused by dynamic processes.

(B) The bubble concentrations measured in the Caroline ice core indicate a difference between the Holocene and this stage between 60 and $64 \mathrm{~m}$, which also contradicts the assumption of dynamic inversion or a repetition process.

On the other hand, difficulties exist in trying to attribute this stage firmly to a given period. According to our interpretation of the dust peak at $55 \mathrm{~m}$ corresponding to -60 ka B.P., this Caroline stage would fit well with Vostok interstage E dated from 73 to 106 ka B.P. (Jouzel and others, 1987). Discontinuities in the ice sequence or much older ice are also quite possible. For example, such discontinuities may occur due to ice-sheet thinning. During warm periods when there is an intense thinning in the margin of the ice sheet, stagnant ice may be formed. The stagnant ice is covered by a slight thickening and readvance of the ice sheet. In this case, discontinuities could be formed. Some large pink particles were found at between 55 and $75 \mathrm{~m}$ depth, possibly the consequence of a dynamic process. Indeed, moraine was found in the D10 ice core which indicated the appearance of a dynamic process.

No moraine exists at the depth where pink particles were found in Caroline ice core, but still the possibility of ice-sheet thinning may be considered. Suppose that during a warm period, intense ice-sheet thinning occurred and that some parts of the bedrock, currently under ice, were exposed to the atmosphere because of the retreat of the ice sheet margin. The big pink particles on the bedrock would be brought to the ice surface by wind. And finally, we cannot exclude the possibility of surging, which could produce discontinuities in the ice sequence. Clearly, we do not have, at the moment, a firm chronology to propose for the ice below $55 \mathrm{~m}$.

\section{CONCLUSION}

It is evident that climatic information is stored even in the marginal zone of the Antarctic ice sheet. The transition from the LGM to the Holocene may be documented from the Caroline core as from other marginal ice cores in Antarctica, although the corresponding isotopic shifts are different from those recorded inland because of the influence of ice-sheet thinning and ice flow. The high isotopic stage accompanied by larger ice crystals, low bubble concentration and low microparticle concentration is probably the consequence of a warm period prior to the LGM.

The LGM low temperature found in most of the ice cores in the margin of East Antarctica was also accompanied by high microparticle concentrations and small ice crystals as found in the Dome C and Vostok cores. LGM is also characterized by high bubble concentrations while warm periods are characterized by low bubble concentrations. A quantitative study of the relationship between climate and bubbles would appear to be a promising approach.

\section{ACKNOWLEDGEMENTS}

We thank L. Augustin, J.M. Barnola and C. Genthon for drilling, field work and ice sampling, M. Creseveur for laboratory assistance and R. Chiron for his assistance in isotopic determinations. We also thank the EPF (Expéditions Polaires Françaises) and TAAF (Terres Australes et Antarctiques Françaises) for their support. The work by T.D. Yao was carried out during a stay at the LGGE and LGI and thanks are extended to the CNRS (Centre National de la Recherche Scientifique) and CEA (Commissariat à l'Energie Atomique) for their financial support.

\section{REFERENCES}

Alley, R.B., J.H. Perepezko, and C.R. Bentley. 1986a. Grain growth in polar ice: I. Theory. J. Glaciol., 32(112), 415424.

Alley, R.B., J.H. Perepezko, and C.R. Bentley. 1986b. Grain growth in polar ice: II. Application. J. Glaciol., 32(112), $425-433$.

Briat, M., A. Royer, J.R. Petit, and C. Lorius. 1982. Late glacial input of eolian continental dust in the Dome C ice core: additional evidence from individual microparticle analysis. Ann. Glaciol., 3, 27-31.

Budd, W.F. and V.I. Morgan. 1977. Isotopes, climate and ice sheet dynamics from core studies on Law Dome, Antarctica. International Association of Hydrological Sciences Publication 118 (Symposium at Grenoble 1975 - Isotopes and Impurities in Snow and Ice), 312-321.

Clausen, H.B. and B. Stauffer. 1988. Analyses of two ice cores drilled at the ice-sheet margin in West Greenland. Ann. Glaciol., 10, 23-27.

De Angelis, M., N.I. Barkov, and V.N. Petrov. 1987. Aerosol concentrations over the last climatic cycle (160 kyr) from an Antarctic ice core. Nature, 325(6102), 318-321.

Duval, P. and C. Lorius. 1980 Crystal size and climatic record down to the last ice age from Antarctic ice. Earth Planet Sci. Lett., 48(1), 59-64.

Gaudichet, A., J.R. Petit, R. Lefevre, and C. Lorius. 1986. An investigation by analytical transmission electron microscopy of individual insoluble microparticles from Antarctic (Dome C) ice core samples. Tellus, 38B(3-4), 250-261.

Gow, A.J. and T. Williamson. 1976. Rheological implications of the internal structure and crystal fabrics of the West Antarctic ice sheet as revealed by deep core drilling at Byrd Station. Geol. Soc. Am. Bull., 87(12), 1665-1677.

Grootes, P.M. and M. Stuiver. 1986. Ross Ice Shelf oxygen isotopes and West Antarctic climate history. Quat. Res., 26(1), 49-67.

Grootes, P.M. and M. Stuiver. 1987. Ice sheet elevation changes from isotope profiles. International Association of Hydrological Sciences Publication 170 (Symposium at Vancouver 1987 - The Physical Basis of Ice Sheet Modelling), 269-281.

Herron, S.L. and C.C. Langway, jr. 1982. A comparison of ice fabrics and textures at Camp Century, Greenland and Byrd Station, Antarctica. Ann. Glaciol., 3, 118-124.

Herron, S.L., C.C. Langway, jr, and K.A. Brugger. 1985. 
Ultrasonic velocities and crystalline anisotropy in the ice core from Dye 3, Greenland. In Langway, C.C., jr, H. Oeschger, and W. Dansgaard, eds. Greenland ice core: geophysics, geochemistry, and the environment. Washington, DC, American Geophysical Union, 23-31. (Geophysical Monograph 33.)

Jouzel, J. and R.A. Souchez. 1982. Melting-refreezing at the glacier sole and the isotopic composition of the ice. $J$. Glaciol., 28(98), 35-42.

Jouzel, J., and 6 others. 1987. Vostok ice core: a continuous isotope temperature record over the last climatic cycle (160,000 years). Nature, 329(6138), 403-408.

Jouzel, J., and 9 others. 1989. A comparison of deep Antarctic ice cores and their implications for climate between 65,000 and 15,000 years ago. Quat. Res., 31(2), $135-150$.

Koerner, R.M. and D.A. Fisher. 1979. Discontinuous flow, ice texture, and dirt content in basal layers of the Devon Island ice cap. J. Glaciol., 23(89), 209-222.

Legrand, M., C. Lorius, N.I. Barkov, and V. Petrov, 1988. Vostok (Antarctica) ice core: atmospheric chemistry changes over the last climatic cycle $(160,000$ years) Atmos. Environ., 22(2), 317-331.

Lorius, C. 1968. A physical and chemical study of the coastal ice sampled from a core drilling in Antarctica. International Association of Scientific Hydrology Publication 79 (General Assembly of Bern 1967 - Snow and Ice), 141-148.

Lorius, C. and L. Merlivat. 1977. Distribution of mean surface stable isotope values in East Antarctica: observed changes with depth in the coastal area. International Association of Hydrological Sciences Publication 118 (Symposium at Grenoble 1975 - Isotopes and Impurities in Snow and Ice), 127-137.

Lorius, C., R. Hagemann, G. Nief, and E. Roth. 1968. Teneurs en deuterium le long d'un profil de $106 \mathrm{~m}$ dans le névé antarctique; application à l'étude des variations climatiques. Earth Planet. Sci. Lett., 4(3), 237-244.

Merlivat, L., C. Lorius, M. Majzoub, G. Nief, and E. Roth. 1967. Etudes isotopiques en profondeur d'un glacier en Antarctique. In Proceedings of the Symposium on the Uses of Isotopes in Hydrology, held in Vienna, 14-18 November 1966. Vienna, International Atomic Energy Agency, 671-681.

Mounier, L. Unpublished. Etude des microparticules insolubles déposées dans la glace antarctique au cours du dernier cycle climatique. (Thèse, Université Joseph Fourier, Grenoble I, 1988.)

Petit, J.R., M. Briat, and A. Royer. 1981. Ice age aerosol content from East Antarctic ice core samples and past wind strength. Nature, 293(5831), 391-394.

Petit, J.R., P. Duval, and C. Lorius. 1987. Long-term climatic changes indicated by crystal growth in polar ice. Nature, 326(6108), 62-64.

Raynaud, D., C. Lorius, W.F. Budd, and N.W. Young. 1979. Ice flow along an I.A.G.P. flow line and interpretation of data from an ice core in Terre Adélie, Antarctica. J. Glaciol., 24(90), 103-115.

Souchez, R., R. Lorrain, J.L. Tison, and J. Jouzel. 1988. Co-isotopic signature of two mechanisms of basal-ice formation in Arctic outlet glaciers. Ann. Glaciol., 10, 163-166.

Thompson, L.G. 1977. Microparticles, ice sheets and climate. Ohio State University. Institute of Polar Studies. Report 64.

Thompson, L.G. and E. Mosley-Thompson. 1981. Temporal variability of microparticle properties in polar ice sheets. Science, 212, 812-815.

Xie Zichu. 1985. Ice formation and ice structure on Law Dome, Antarctica. Ann. Glaciol., 6, 150-153.

Young, N.W., Xie Zichu, and Qin Dahe. 1985. Multilayer crystallographic structure of Law Dome from ice core analysis. ANARE Res. Notes 28, 18-24. 